\title{
On the Dilemma and the Paths of Management Accounting's Innovation and Development from the Perspective of Informatization 2.0
}

\author{
Huiqun Wang \\ College of Economics and Management, Nanjing University of Aeronautics and Astronautics, P.R. China \\ Corresponding author. Email: $524798120 @ q q . c o m$
}

\begin{abstract}
With the rapid development of China's economy and society, the scale of enterprises in various industries is constantly expanding. As the booster of quality and efficiency of enterprise, the upgrading of management accounting (MA) has become an inevitable trend of enterprise innovation and development in informatization 2.0. Based on history analysis and literature research of MA, the paper investigates the current situation of MA, and explores the problems of MA application in China, and draws conclusions that there are some difficulties existed in MA application, such as the weak foundation of informatization, the neglect of enterprise leaders and the low level of accounting quality. The research shows that the innovation and development of MA is an important support for enterprises to remain invincible in fierce economic competition. The paper then discusses strategic approaches to strengthen practical application of MA from external and internal aspects, such as speeding up the transformation of financial accounting, adopting the means of computerization, eliminating the information islands and strengthening the information security management, so as to provide guarantee for enterprise sustainable development.
\end{abstract}

Keywords: Informatization 2.0, Management Accounting (MA), Enterprise, Dilemma, Route.

\section{BACKGROUND OF MA: SITUATION AND CURRENT SITUATION}

\subsection{Concept of MA}

Management accounting (MA) is a branch of modern accounting, which was developed by the combination of management and accounting in the 1950s. As an emerging discipline, MA is recognized as an epoch-making milestone in the development of modern accounting history, marking that modern accounting has entered a new stage of development. In the late 1970s, China began to systematically introduce the theories and methods of Western MA. Compared with the financial accounting based on the national accounting standards, MA highlights the management function. MA includes analyses of nonfinancial resources, including manufacturing and sales performance data, and a range of techniques for managing costs [1]. In the social and economic environment, the enterprise managers need to set short-term and long-term development goals for the enterprise according to the development trend of the industry. The work content of MA includes the use of management accounting knowledge, accurate analysis of enterprise development and market conditions, providing data support for managers to make enterprise development decisions, and making future business decisions more scientific.

\subsection{Transformation and Upgrading of MA}

Nowadays, the world economy is facing a new economic environment, which is characterized by internationalization, financialization and intellectualization on the macro-level. From the microlevel, it is transforming from the industrial society to the information society, and the business environment of enterprises has undergone tremendous changes. With the rapid development of cloud computing, big data, Internet of things and mobile commerce, enterprise management mode has broken time and space constraints [2]. Since the invention of digital computer in 1946, human society has experienced two informatization movements. The first one is dominated by American information enterprises 
represented by IOE (IBM, Oracle, EMC), and the second is initiated by Chinese enterprises. The change of industrial rules has promoted Chinese enterprises' "de-IOE", and enterprise management has entered Information 2.0 era. The NDRC and CAC have issued an implementation plan to deeply implement the digital economy strategy and accelerate the digital industrialization and industry digitization [3], which promotes enterprises to develop emerging industries and transform to informatization, and improve the level of decision-making.

Modern accounting is responsible for forecasting, decision-making, planning, control, assessment, evaluation and other functions. There is more and more room for the further improvement of the basic theory, basic methods and practical operation technology of MA. The transformation from financial accounting to management accounting is an important road to reduce operating costs, avoid operating risks and improve the competitiveness of enterprises [4]. The application scope of information technology in MA is greatly broadened. MA can accurately analyze information data, accurately predict market dynamics, provide decision-making basis for enterprises, and promote the smooth operation of enterprises and the improvement of core competitiveness.

\subsection{Analysis of Current Situation of MA}

Since the late 1970s, MA has been carried over into China's economic system, constantly improved and played an irreplaceable role. Some enterprises and organizations have introduced Western MA theories and methods, and set up special MA organization system, cost target profit assessment mechanism, cost difference analysis and so on, which have achieved preliminary results in application. As a branch of accounting, MA supports enterprise decision-making around standard cost control, budget control, responsibility accounting, performance appraisal, cost volume profit analysis and prediction decisionmaking. It has become an important part of modern enterprise accounting system and a subsystem of information system providing management information to enterprise leaders. Some large enterprises have absorbed MA in enterprise top economic organization, set up MA institutions to involve into decision-making.

\section{PROBLEMS IN MA: SHORTCOMING AND DILEMMA}

\subsection{Limitations of Discipline Development}

The limitation of MA discipline hinders the enthusiasm of accountants in MA using. The first reason is to attach importance to theoretical education and neglect practical application. Both the academic education and non-academic education of MA in our country pay attention to the teaching of theory and methods, and ignore the case analysis within enterprises, which makes many accountants think that MA theory is too difficult to learn, and has no application value in reality. The second, quantitative analysis is emphasized and qualitative analysis is ignored. Overemphasizing the former leads to the phenomenon that theory is divorced from practice. Even some simple principles are often demonstrated and expressed by abstruse and complicated higher mathematics formulas so as to ignore the interpretation of the economic significance behind numbers. The third is to focus on result calculation and ignore data analysis. The mode application and result calculation are placed in the first place, ignoring the premise analysis of the model application and the data retrieval process of result calculation. Accountants either do not know how to obtain the relevant data, or do not know the preconditions of the mode. The errors between result and fact often take place and the results lose reference value of decision-making.

\subsection{Difficulty of MA Promotion}

MA promotion has met with some difficulties and problems in practice. First, the theoretical system is not perfect. Both theories and methods of Western MA have not been completely refined. In our country, a systematic theoretical system has also not been built, which is affecting its promotion and application in enterprises. There are few monographs on the theoretical research, and the related research lags behind because of lacking of high-level theoretical researchers. The existing application experience of MA has not been summarized from the perspective of the combination of theory and practice. Second, accounting methods of enterprises are also backward. Some enterprises still use traditional manual bookkeeping method. Although some enterprises have adopted computerization, the application degree and utilization efficiency of computers are not relatively high. On the other hand, most of the computer software may be only suitable for financial accounting system. Third, the quality level of enterprise managers and accounting employees need improving. The 
decision-makers of enterprises are not aware of the importance of MA. Some entrepreneurs are used to taking financial accounting departments as economic accounting units. The perceptions of accounting staff fall behind the times and their MA knowledge level is weak. Survey data show that in some large and medium-sized enterprises, accounting employees with college level or above only account for about $20 \%$, and many employees lack data analysis ability.

\subsection{Lag of Information Platform Construction}

Many enterprises are hesitant in face with the trend of informatization 2.0. First, the infrastructure of information platform is backward. Most manufacturing enterprises need to make continuous efforts in ICT infrastructure, operation and maintenance. Research shows that under the policy background of vigorously promoting industry 4.0 in China, $84.9 \%$ of manufacturing industries are undergoing digital transformation, but the comprehensive success rate of digital transformation is less than 40\%. In 2020, when COVID-19 suddenly came, entrepreneurs began exploring digitalization, trying to shift their offline businesses to online businesses so as to resist possible risks. Second, data islands exist. The emergence of data islands lies in the lack of global data thinking in enterprise information construction. The independent servers (desktop, standard server, etc.) of each business system are placed in different departments of the enterprise, and they are divided into independent parts.

\subsection{Network Information Security Faultiness}

MA information reserve and safety have a direct impact on the transformation of modern enterprise accounting work. The vast majority of enterprises do not pay special attention to the storage and security of accounting data. The storage and distribution of data is relatively scattered, and its integrity and security cannot be effectively guaranteed, which has a negative effect on the data integration and analysis of MA. Due to ineffective preventive measures of data security, more and more data stored and transmitted through electronic media suffer from the risk of loss or theft. The illegal actions of network hackers and competitors also cause immeasurable risks. Nowadays special software platforms or warning systems for MA information reserve and security are still not mature enough.

\section{SUGGESTIONS FOR THE DEVELOPMENT OF MA: PATHS AND STRATEGIES}

\subsection{Optimize External Environment of Enterprise and Let MA Enter Enterprises}

\subsubsection{Enhancing the internal driving}

Modern enterprise systems should be established to enhance the internal driving force of MA. The prerequisite of MA application is a mature market system and a concordant mechanism with clear rights and responsibilities, separation of government and enterprise. From the analysis of the external environment of enterprises, the unclear property rights of enterprise at present leads to the fact that the government and enterprises are not separated and the responsibilities are not clear, so MA is useless in enterprise management. To clear the bottleneck, it is necessary to clarify and establish a modern enterprise system, clarify the relationship between property rights, and place enterprises in real market environment.

\subsubsection{Increasing the practicability of $M A$ theory}

The theoretical systems of the discipline should be improved to increase the practicability. Theory teaching of MA should be integrated into the practice of enterprises to enhance its universality. Investigation shows that MA theory can be better implemented, improved and applied with the cooperation of accountants. Due to the differences between the external and internal environment of enterprises, management methods vary from enterprise to enterprise, we should adopt different approaches to improve MA operability.

\subsubsection{Establishing relevant management institution and systems}

Relevant management institutions and systems should be established to enhance the mandatory application. Due to the lack of targeted legal and institutional issues, it often receives enterprise leaders' neglect or contempt. We should promulgate relevant management policies, laws and regulations, establish appropriate management organizations, and implement MA systems. Although China's accounting circles have successively established some accounting academic and practical organizations, such as Accounting Society of China, the Chinese Institute of 
Certified Public Accountants, China Cost Research Society, Research Association of China Chief Financial Officer, there is still a lack of a specialized MA academic research organization. The industry standards of MA have not been established effectively. So we should learn from the Western experience, establish a special academic group or organization of MA to organize and guide MA research and application.

\subsection{Optimize the Internal Mechanism and Make MA Rooting in Enterprises}

\subsubsection{Constructing Enterprise leaders' new awareness of $M A$}

Managers of enterprises should renew their ideas and improve strategic awareness of future development. Under the global fierce competition, if enterprises want to survive and develop, they must make scientific prediction, planning and decisionmaking for their business activities. The lack of MA may not have a great impact on the short-term operation and development of enterprises, but in the long run, it will certainly affect and restrict the innovation and development of enterprises [5]. Enterprise leaders must speed up the renewal and transformation of ideas and actively integrate MA into enterprise internal management.

\subsubsection{Strengthening the construction and application of information platforms}

The construction and application of information platforms should be strengthened to eliminate the phenomenon of information islands. Enterprise informatization is a systematic project. The integration of ICT infrastructure is the core foundation of enterprise information construction. We should make a unified planning from the strategic development direction of the enterprise, and build information platforms and neural network based on the modular architecture, edge computing equipment and other ICT infrastructure by taking advantage of cloud computing, big data and other intelligent technologies.

\subsubsection{Upgrading MA employees' quality and abilities}

MA employees' quality should be improved to enhance their abilities of participating in business decision-making. Nowadays the function of accounting should cover the whole process of enterprise management, such as the prediction in advance, the control in the event, and the assessment after the event. Accounting employees should not only have profound accounting abilities, but also have certain management and organizational abilities [6]. Enterprises should actively promote the transformation from financial accounting to management accounting, and pay attention to the selection, training of employees with MA knowledge and skills, organizational ability, and strong sense of innovation.

\subsubsection{Developing computerized accounting information systems}

Accounting computerization should be used to optimize the ecological environment of MA application. The popularization of MA not only can strengthen the basic accounting work such as original records, quota management, measurement and detection, but also can realize the leap of accounting information means and ensure the authenticity and timeliness of accounting information [7]. The software of MA should be developed towards computerization. Computer's fast calculation ability and analysis ability not only simplifies complicated accounting calculation in the daily work, but also improves calculation accuracy of MA and greatly reduces the workload of accounting daily work.

\subsubsection{Reinforcing accounting information security and data protection}

Accounting information reserve and data security should be strengthened. The management accounting information not only includes the basic financial data information, but also covers the data information and market information generated in the operation of the enterprise. It is necessary for enterprises to comprehensively improve the data information reserve and security work, formulate scientific and sound information reserve and security management systems, strengthen, and ensure no online or offline loopholes.

\section{CONCLUSION}

The innovation and development of MA is an important support for enterprises to remain invincible in the fierce economic competition. The improvement of economic benefits and stable development of enterprises are inseparable from the reasonable planning of capital construction. Localization of MA theory and practice is a long-term project. We should unremittingly push on the research and application. Enterprise must recognize the value advantages of MA and constantly strengthen the functions and solve the 
external and internal problems in an all-round way. To sum up, in the background of information 2.0, innovation and development of MA can contribute to the progress of governance abilities of modern enterprises, and can be in favor of enterprises' healthy and stable development. To change the external and internal environment of MA implementation and achieve the accuracy of decision-making, modern enterprises should absorb strategic paths of updating the concept of management employees, introducing new and efficient theories and methods, building information platforms, adopting advanced accounting computerization, strengthening information reserve and safety, and carrying on high-quality professional training.

\section{AUTHORS' CONTRIBUTIONS}

The author conceived and designed the study, collected related data and conducted research, wrote initial draft and final draft of this manuscript.

\section{ACKNOWLEDGMENTS}

The author would like to thank all of the reviewers and editors of the 2021 ICTIBE for their kind feedback and help with this manuscript.

\section{REFERENCES}

[1] K. Langfield-Smith, H. Thorne, D. Smith, Management accounting: information for creating and managing value, McGraw-Hill Education (Australia) Pty Ltd, North Ryde, 2015

[2] Qing Feng Yang, Informatization 2.0+: informatization system in the cloud computing era, Publishing House of Electronics Industry, Peking, 2013

[3] NDRC \& CAC: the National Development and Reform Commission, Cyberspace Administration of China, the Implementation Plan on Promoting the Action of Using Cloudplatform, and Big Data to Endow Wisdom to Cultivate New Economic Development, Peking, 2020. DOI: https:// www.ndrc.gov.cn/xxgk/zcfb/tz/202004/t202004 10_1225542.html

[4] Jin feng Chen, On the Transformation of enterprise financial accounting to management accounting in the age of artificial intelligence, in: Modern Business,
Peking, vol.15, 2020, pp. 181-182. DOI : CNKI: SUN: XDBY.0.2020-17-082

[5] JF Henri, Management control systems and strategy: a resource-based perspective, in: Accounting Organizations and Society, vol.31, 2005, pp. 529-558. DOI: https://doi.org/10.1016/j.aos.2005.07.001

[6] T. Malmi, Towards explaining activity-based costing failure: accounting and control in decentralized organization, in: Management Accounting Research, Elsevier B.V, Vol 4, 1997 , pp. 459-480. DOI: https://doi.org/10. 1006/mare.1997.0057

[7] Joe Nandhakumar, Matthew Jones, Accounting for time: managing time in project-based teamworking, in: Accounting Organizations and Society, Oxford, 2001, pp. 193-214. DOI: https://doi.org/10.1016/S0361-3682(99)00051-3 